Int. J. Electrochem. Sci., 15 (2020) $879-888$

\title{
Effect of Ethanolamine on Corrosion Behavior of WB36CN1 Steel in Simulated Secondary Circuit of Pressurized Water Reactor
}

\author{
Jian Song, Zhiming Gao*, Chenxi Liu, Zhihong Liu, Wenbin Hu \\ School of Material Science and Technology, Tianjin University, Tianjin, 30072, China \\ Engineering Research Center of Composite and Functional Materials, Ministry of Education, Tianjin, \\ 30350, China \\ *E-mail: gaozhiming@tju.edu.cn
}

doi: $10.20964 / 2020.01 .56$

Received: 5 September 2019 / Accepted: 30 October 2019 / Published: 30 November 2019

\begin{abstract}
Effect of ethanolamine (ETA) on corrosion behavior of WB36CN1 low alloy steel in simulated pressurized water reactor (PWR) secondary circuit conditions was studied by electrochemical methods, scanning electron microscopy (SEM), 3D microscopy, and X-ray Photoelectron Spectroscopy (XPS). The polarization curve indicated that ETA can inhibit the cathode and anode processes, and corrosion current density decreased with increasing ETA concentration. EIS results showed that the charge transfer resistance and the oxide film resistance increased with increasing ETA concentration. The XPS results indicated that the main compositions of oxide film on the WB36CN1 steel were both $\mathrm{Fe}_{3} \mathrm{O}_{4}$ in the different solution (no ETA and 24ppm). SEM analysis suggested that the film oxide became more dense with increasing ETA concentration. Thus, the corrosion rate of WB36CN1 low alloy steel in the secondary circuit of PWR decreased with an increase of ETA concentration.
\end{abstract}

Keywords: WB36CN1 steel, PWR secondary circuit, ETA, SEM, XPS

\section{$\underline{\text { FULL TEXT }}$}

(C) 2020 The Authors. Published by ESG (www.electrochemsci.org). This article is an open access article distributed under the terms and conditions of the Creative Commons Attribution license (http://creativecommons.org/licenses/by/4.0/). 